\title{
Mass Interception Fractions and Weathering Half-lives of Iodine-131 and Radiocesium in Leafy Vegetables Observed after the Fukushima Daiichi Nuclear Power Plant Accident
}

\author{
Keiko Tagami, Shigeo Uchida \\ National Institute of Radiological Sciences, National Institute for Quantum Science and Technology, Chiba, Japan
}

\section{Original Research}

Received April 19, 2021

Revision June 15, 2021

Accepted July 19, 2021

Corresponding author: Keiko Tagami

National Institutes for Quantum and Radiological Science and Technology, Anagawa 4-9-1, Inage-ku, Chiba-shi, Chiba 263-8555, Japan

E-mail:Tagami.keiko@qst.go.jp

(iD https://orcid.org/0000-0002-9139-444

This is an open-access article distributed under the terms of the Creative Commons Attribution License (http://creativecommons.org/licenses/by-nc/4.0), which permits unrestricted use, distribution, and reproduction in any medium, provided the original work is properly cited.

Copyright $\odot 2021$ The Korean Association for Radiation Protection

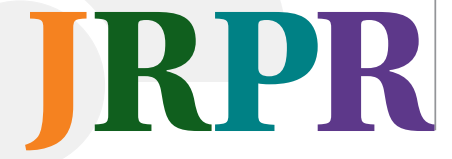

Background: This study was carried out to provide environmental transfer parameter values to estimate activity concentrations of these radionuclides in agricultural crops when direct contamination occurred.

Materials and Methods: Mass interception fractions $\left(F_{B} \mathrm{~S}\right)$ and weathering half-lives $\left(T_{w} \mathrm{~s}\right)$ of ${ }^{131} \mathrm{I}$ and radiocesium were calculated using openly available monitoring data obtained after the Fukushima Daiichi Nuclear Power Plant accident. $F_{B}$ is the ratio between the initial radioactivity concentration of a radionuclide retained by the edible part of the plant $\left(\mathrm{Bq} \cdot \mathrm{kg}^{-1}\right.$ fresh weight $[\mathrm{FW}])$ and the amount of deposited radionuclide in that area $\left(\mathrm{Bq} \cdot \mathrm{m}^{-2}\right) . T_{w}$ values can be calculated using activity concentrations of crops decreased with time after the initial contamination.

Results and Discussion: Calculated $F_{B}$ and $T_{w}$ values for ${ }^{131} \mathrm{I}$ and radiocesium were mostly obtained for leafy vegetables. The analytical results showed that there was no difference of $F_{B}$ between ${ }^{131} \mathrm{I}$ and radiocesium by $t$-test; geometric mean values for leafy vegetables cultivated under outdoor conditions were 0.058 and $0.12 \mathrm{~m}^{2} \cdot \mathrm{kg}^{-1} \mathrm{FW}$, respectively. Geometric mean $T_{w}$ value of ${ }^{131} \mathrm{I}$ in leafy vegetables grown under outdoor conditions was 8.6 days, and that of radiocesium was 6.6 days; there was no significant difference between $T_{w}$ values of these radionuclides by Wilcoxon rank sum test.

Conclusion: There was no difference between ${ }^{131} \mathrm{I}$ and radiocesium for $F_{B} S$ and $T_{w}$ s. By using these factors, we would be able to carry out a rough estimation of the activity concentrations of ${ }^{131} \mathrm{I}$ and radiocesium in the edible part of leafy crops when a nuclear accident occurred.

Keywords: Mass Interception Fraction, Weathering Half-Life, Leafy Vegetable, Iodine-131, Radiocesium

\section{Introduction}

Agricultural crops were directly contaminated with radioactive fallout due to the TEPCO's Fukushima Daiichi Nuclear Power Plant (FDNPP) accident that occurred on March 11, 2011. In affected areas, such as Fukushima Prefecture and its surrounding prefectures, activity concentrations of ${ }^{131} \mathrm{I}\left(\mathrm{T}_{1 / 2}=8.02\right.$ days $)$ and radiocesium $\left({ }^{134} \mathrm{Cs}: \mathrm{T}_{1 / 2}=\right.$ 2.065 years $+{ }^{137} \mathrm{Cs}: \mathrm{T}_{1 / 2}=30.2$ years) in some leafy vegetable samples exceeded the provisional limits at that time, 2,000 Bq $\mathrm{kg}^{-1}$ and $500 \mathrm{~Bq} \cdot \mathrm{kg}^{-1}$, respectively (from April 1, 2012, the standard limit for total radiocesium was set to $100 \mathrm{~Bq} \cdot \mathrm{kg}^{-1}$ ). When the radioactivity 
concentration(s) in a crop sample in a certain municipality exceeded the limit, the municipality was not allowed to sell their crop products. Then, once a week, radioactivity monitoring needed to be carried out to confirm that the activity concentration data obtained in the following continuous 3 weeks were lower than the limit values, which were the required conditions to sell and to eat the products again.

When a new nuclear accident happens, we can use the monitoring data obtained in 2011 to estimate the initial radioactivity levels in leafy vegetables and how fast the radioactivity in the crops would decrease with time. For that purpose, it is better to parameterize the related factors, that is, mass interception fractions $\left(F_{B} \mathrm{~S}\right)$ and weathering half-lives $\left(T_{w} \mathrm{~s}\right)$. Following deposition of radionuclides on vegetables, the initial radionuclide activity concentrations of the vegetables can be estimated by $F_{B}$, which is the ratio between the initial radioactivity concentration of a radionuclide retained by the edible part of the plant (Bq $\mathrm{kg}^{-1}$ fresh weight $[\mathrm{FW}]$ ) and the amount of deposited radionuclide in that area $\left(\mathrm{Bq} \cdot \mathrm{m}^{-2}\right)$. $T_{w}$ is the time taken for the quantity of radionuclides on and in plants to be reduced by half due to weathering (rain and window), tissue ageing, mass increase, and other processes. Thus, following activity concentrations in the vegetable can be estimated using $T_{w}$.

These parameter data were available in the International Atomic Energy Agency (IAEA) Technical Report Series No. 472 (TRS 472) [1]; the values were originally from laboratory experiments and observation results after the Chernobyl accident. Recently published technical document of the IAEA No. 1927 (TECDOC 1927) [2] summarized the $F_{B}$ and $T_{w}$ observed after the FDNPP accident, but no detailed analysis was reported yet. Therefore, in this study, we have re-collated these values and checked the differences among crop species.

\section{Materials and Methods}

Because the radioactivity monitoring of fresh vegetables was not carried out immediately after the FDNPP accident started, it was difficult to obtain the initial activity concentrations in those vegetables. According to the TECDOC 1927 [2], we can back-calculate the initial activity concentrations from continuous monitoring data, which were available from the food monitoring results in March to April 2011 reported by the Ministry of Health, Labour and Welfare (MHLW), Japan [3]. The image of the calculation is shown in Fig. 1.

The exponential decline in radioactivity concentration in

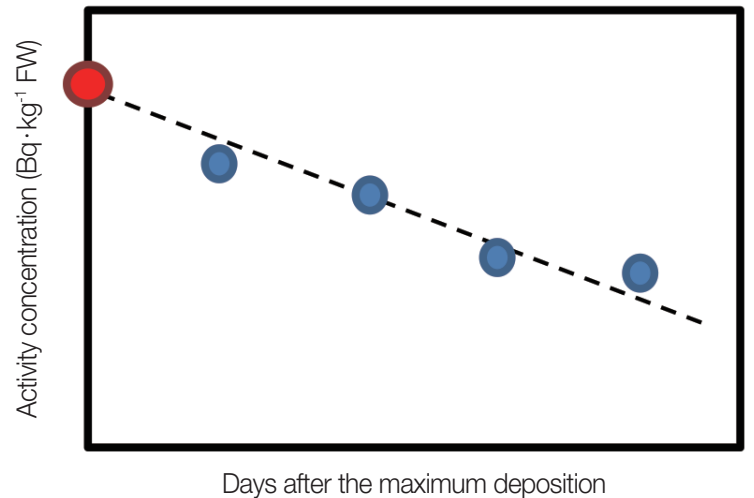

Fig. 1. An image of back-calculating method to obtain initial radioactivity concentration (red) of a radionuclide in leafy vegetable. The dotted line (fitting result of the continuous monitoring data) was used to calculate weathering half-life. FW, fresh weight.

the edible part of the crop over time is explained as follows.

$$
A_{t}=A_{0} \exp \left(-\lambda_{\text {eff }} t\right)
$$

where $A_{t}$ is activity concentration $\left(\mathrm{Bq} \cdot \mathrm{kg}^{-1} \mathrm{FW}\right)$ of ${ }^{131} \mathrm{I},{ }^{137} \mathrm{Cs}$ or total radioactive Cs $\left({ }^{134} \mathrm{Cs}+{ }^{137} \mathrm{Cs}\right)$ at time $t$ (day), $A_{0}$ is the expected initial activity concentration $\left(\mathrm{Bq} \cdot \mathrm{kg}^{-1} \mathrm{FW}\right)$, and $\lambda_{\text {eff }}$ is the radionuclide loss rate constant. Using the concentration data, a best fit exponential line for each leafy vegetable sample set collected in a certain municipality was calculated using KaleidaGraph software version 4.5 (Synergy Software, Reading, PA, USA).

Using $A_{0}$ and total deposition amounts in the area $A_{s}$ $\left(\mathrm{Bq} \cdot \mathrm{m}^{-2}\right)$, mass interception fraction $F_{B}$ is calculated as follows.

$$
F_{B}=\frac{A_{0}}{A_{s}}
$$

For radiocesium, $A_{s}$ was calculated using the second soil monitoring results among nine sampling campaigns carried out in 2011-2016 by in situ Ge gamma-ray spectrometry, which was conducted for ${ }^{134} \mathrm{Cs}$ and ${ }^{137} \mathrm{Cs}$ (decay corrected to March 1, 2012). Details of the soil data are found in our report [4]. For ${ }^{131}$ I, we used activity concentrations of measured ${ }^{131} \mathrm{I}$ in soil and estimated ${ }^{131} \mathrm{I}$ from ${ }^{129} \mathrm{I}$ in soil carried out by the Ministry of Education, Culture, Sports, Science and Technology and the Nuclear Regulation Authority, Japan [5]. All the data for ${ }^{131} \mathrm{I},{ }^{134} \mathrm{Cs}$, and ${ }^{137} \mathrm{Cs}$ were corrected to March 20, 2011 because the heaviest radioactivity deposition was observed in large areas in eastern Japan on March 20-22 [6]. Corresponding soil data were based on data in each municipality 
in Fukushima Prefecture and the geometric mean value was calculated to obtain $A_{s}$ values. For other areas, if there were no corresponding data for ${ }^{131} \mathrm{I}$ and radiocesium in a municipality, then the data in each prefecture's deposition monitoring site were applied.

To calculate $T_{w}$, effective half-life ( $T_{e f f}$, in day) needs to be calculated first using $\lambda_{\text {eff }}$ as follows.

$$
T_{e f f}=\frac{\ln 2}{\lambda_{\text {eff }}}
$$

The $T_{\text {eff }}$ is expressed as follows.

$$
\frac{1}{T_{e f f}}=\frac{1}{T_{w}}+\frac{1}{T_{p}}
$$

where $T_{p}$ is the physical half-life of the radionuclide. Using these equations, $T_{w}$ is then calculated as follows.

$$
T_{w}=T_{e f f} \times \frac{T_{p}}{T_{p}-T_{e f f}}
$$

We checked the correlation factor between time (day) and the logarithm of the activity concentrations by Student $t$-test to accept the data set for $F_{B}$ and $T_{w}$ calculations or not. Firstly based on $p$-values, we considered that if $p<0.05$ and the coefficient of determination $\left(\mathrm{R}^{2}\right)$ value was higher than 0.6 , then the data set was used for $T_{\text {eff }}$ calculation. Next, if $\mathrm{R}^{2}$ was higher than 0.9, then we included the data set to calculate $T_{\text {eff }}$ even if $p$-values were more than 0.05 .

\section{Results and Discussion}

After examination of the food monitoring results by MHLW [3], leafy vegetable data obtained in Fukushima Pre- fecture and surrounding five prefectures (Chiba, Gunma, Ibaraki, Saitama, and Tochigi) were found. Numbers of data sets used for decline fittings by Equation (1) were 15 for radiocesium (eight datasets were from Fukushima Prefecture), and 42 for ${ }^{131} \mathrm{I}$ (19 datasets were from Fukushima Prefecture). Crops were celery, crown daisy, Japanese honeywort, kakina, komatsuna, kukitachina, mizuna, parsley, shinobufuyuna, shiso, and spinach. For comparison, we included heads of cabbage and flowering shoots of Brassica species (e.g., broccoli). Additional data from our experiments for giant butterbur [6] were also included in the analysis. Summary of the data analysis carried out using JMP 9.0 (SAS Institute Inc., Cary, NC, USA) is shown in Supplementary Table S1.

\section{Mass Interception Fractions of ${ }^{131} I$ and Radiocesium}

By applying Equation (1), we successfully obtained $A_{0}$ values for crops mentioned above with good fitting results. However, because some areas were difficult to find corresponding total deposition data, $A_{s}$, thus, the numbers of $F_{B}$ values were smaller compared to those listed above. In addition to the $F_{B}$ calculation using openly available data sets, because we measured edible wild plants on March 28, 2011 and deposition samples [7], the data were also included for analysis.

$F_{B}$ values should be affected by the plant shape (e.g., cabbage, spinach) and the cultivation conditions, i.e., outside and indoor (greenhouse and tunnel) cultivations, thus $F_{B}$ data were summarized in the leafy vegetables and other shape green vegetables (head and flowering shoots), and also classified into outdoor and indoor cultivations, if possible. The $F_{B}$ data are summarized in Table 1; because we lacked knowledge about the distribution characteristics of the data for all groups,

\begin{tabular}{|c|c|c|c|c|c|c|c|c|}
\hline \multirow{2}{*}{ Radionuclide } & \multirow{2}{*}{$\begin{array}{l}\text { Cultivation } \\
\text { condition }\end{array}$} & \multirow{2}{*}{ Crop type } & \multirow{2}{*}{$n$} & \multicolumn{5}{|c|}{$F_{B}\left(\mathrm{~m}^{2} \cdot \mathrm{kg}^{-1} \mathrm{FW}\right)$} \\
\hline & & & & AM & SD & GM & GSD & Range \\
\hline \multirow[t]{4}{*}{ Cs } & \multirow[t]{3}{*}{ Outdoor } & Leafy vegetables & 15 & 0.210 & 0.220 & 0.130 & 2,8 & $0.020-0.720$ \\
\hline & & (Spinach) & 6 & 0.250 & 0.270 & 0.140 & 3.4 & $0.026-0.720$ \\
\hline & & Other green vegetables & 2 & 0.082 & 0.060 & 0.070 & 2.2 & $0.040-0.120$ \\
\hline & Indoor & Leafy vegetables & 4 & 0.014 & 0.010 & 0.011 & 2.2 & $0.005-0.028$ \\
\hline \multirow[t]{5}{*}{ । } & \multirow[t]{3}{*}{ Outdoor } & Leafy vegetables & 28 & 0.092 & 0.091 & 0.057 & 2.8 & $0.012-0.300$ \\
\hline & & (Spinach) & 15 & 0.063 & 0.048 & 0.048 & 2.2 & $0.012-0.200$ \\
\hline & & Other green vegetables & 9 & 0.008 & 0.007 & 0.005 & 3.9 & $0.001-0.022$ \\
\hline & \multirow[t]{2}{*}{ Indoor } & Leafy vegetables & 11 & 0.039 & 0.052 & 0.015 & 5.7 & $0.001-0.140$ \\
\hline & & (Spinach) & 4 & 0.046 & 0.061 & 0.025 & 3.2 & $0.010-0.140$ \\
\hline
\end{tabular}

Table 1. Mass Interception Fractions $\left(F_{B}\right)$ of Radiocesium and ${ }^{131} \mathrm{I}$ and for Leafy Vegetables Observed after the Fukushima Daiichi Nuclear Power Plant Accident in 2011

FW, fresh weight; $n$, sample size; AM, arithmetic mean; SD, standard deviation; GM, geometric mean; GSD, geometric standard deviation. 
arithmetic mean (AM), standard deviation (SD), geometric mean (GM), and geometric standard deviation (GSD) are provided with ranges of the $F_{B}$ data. Using the sample groups having the largest $n$ for ${ }^{131} \mathrm{I}$ and radiocesium were examined for their data distribution. Based on the Shapiro-Wilk normality test result, the $F_{B}$ of leafy vegetables cultivated under outdoor conditions did not follow a normal distribution for each radionuclide. When the logarithms of the $F_{B}$ data were calculated, the data agreed to a log-normal distribution for each radionuclide. We assumed that log-normal distributions were suitable for other groups, thus, data comparisons were carried out using the logarithm of the $F_{B}$ data.

From the results for $F_{B}$ of Cs, leafy vegetables cultivated under outdoor conditions tended to show higher values ( $\mathrm{GM}=$ $\left.0.13 \mathrm{~m}^{2} \cdot \mathrm{kg}^{-1} \mathrm{FW}\right)$ than that for other green vegetables ( $\mathrm{GM}=$ $0.07 \mathrm{~m}^{2} \cdot \mathrm{kg}^{-1} \mathrm{FW}$ ) but the numbers of data were too small for statistical analysis. For $F_{B}$ of ${ }^{131}$ I, the logarithm of the data for leafy vegetables cultivated under outdoor conditions ( $\mathrm{GM}=$ $0.057 \mathrm{~m}^{2} \cdot \mathrm{kg}^{-1} \mathrm{FW}$ ) was significantly higher than those from indoor cultivation $\left(\mathrm{GM}=0.015 \mathrm{~m}^{2} \cdot \mathrm{kg}^{-1} \mathrm{FW}\right)$ by Wilcoxon rank sum test $(p=0.018)$. However, when we used the data only for spinach, no difference was found between these different cultivation conditions. When the data of leafy vegetables were compared to those of other green vegetables both grown under outdoor conditions, a significant difference was observed by the same test $(p<0.001)$. From these results, we assumed that crop type (shape) and/or species would affect the $F_{B}$ value rather than cultivation conditions.

For leafy vegetables grown under outdoor conditions, the $F_{B}$ data for radiocesium were significantly higher than those for ${ }^{131}$ I by Wilcoxon rank sum test $(p=0.023)$. According to IAEA TRS 472 [5], $F_{B}$ values for grass observed after the
Chernobyl accident were $1.1 \mathrm{~m}^{2} \cdot \mathrm{kg}^{-1}$ dry weight for Cs and $0.7 \mathrm{~m}^{2} \cdot \mathrm{kg}^{-1}$ dry weight for I, thus $F_{B}$ of Cs was slightly higher. Our present results showed a similar tendency; however, more specifically, we compared the $F_{B}$ values for spinach. The result showed no difference between ${ }^{131} \mathrm{I}$ and radiocesium by Wilcoxon rank sum test ( $p>0.05)$. From these results, although the chemical forms of ${ }^{131} \mathrm{I}$ and radiocesium were different, $F_{B}$ values were not much different. Yet, further studies are needed to clarify the chemical form effect on $F_{B}$ values by plants.

Values in IAEA TRS 472 were collated on a dry weight basis; thus, it was difficult to compare the data directly with our data. Fresh mass to dry mass conversion factors are needed for this comparison; according to the TRS 472, dry matter contents for grass species (e.g., Timothy grass, Standard crested grass, Meadow fescue) were $20 \%-39 \%$. When the median value, ca. $30 \%$ was used to calculate $\mathrm{FW}$ basis $F_{B}$ for grass in IAEA TRS 472, the calculated values were 0.33 $\mathrm{m}^{2} \cdot \mathrm{kg}^{-1} \mathrm{FW}$ for Cs, and for $0.21 \mathrm{~m}^{2} \cdot \mathrm{kg}^{-1} \mathrm{FW}$ for I. The GM of $F_{B}$ values for radiocesium and ${ }^{131} \mathrm{I}$ in the present study was about one-third of the TRS 472 values, respectively, probably because only edible parts were considered in this study.

\section{Weathering Half-lives of ${ }^{131} \mathbf{I}$ and Radiocesium}

$T_{w}$ data were calculated using Equations (3)-(5), and the summaries of the results are shown in Table 2. Similar to the $F_{B}$ data analysis, using the sample group having the largest $n$ was examined for its data distribution, and we found that the data distributed log-normally. Thus for $T_{w}$ data, we also assumed that all data would distribute log-normally thus logarithm of the $T_{w}$ data were used for analysis.

$T_{w}$ values of ${ }^{131} \mathrm{I}$ in leafy vegetables obtained under outdoor

Table 2. Weathering Half-life $\left(T_{w}\right)$ of Radiocesium and ${ }^{131} \mathrm{I}$ and for Leafy Vegetables Observed after the Fukushima Daiichi Nuclear Power Plant Accident in 2011

\begin{tabular}{|c|c|c|c|c|c|c|c|c|}
\hline \multirow{2}{*}{ Radionuclide } & \multirow{2}{*}{$\begin{array}{l}\text { Cultivation } \\
\text { condition }\end{array}$} & \multirow{2}{*}{ Crop type } & \multirow{2}{*}{$n$} & \multicolumn{5}{|c|}{$T_{w}(\mathrm{~d})$} \\
\hline & & & & AM & SD & GM & GSD & Range \\
\hline \multirow[t]{4}{*}{ Cs } & \multirow[t]{3}{*}{ Outdoor } & Leafy vegetables & 11 & 6.5 & 1.9 & 6.2 & 1.4 & $3.1-8.9$ \\
\hline & & (Spinach) & 6 & 6.7 & 2.0 & 6.3 & 1.5 & $3.1-8.9$ \\
\hline & & Other green vegetables & 2 & 6.8 & 1.4 & 6.7 & 1.2 & $5.8-7.8$ \\
\hline & Indoor & Leafy vegetables & 5 & 13.0 & 5.0 & 12.0 & 1.4 & $8.6-21.0$ \\
\hline \multirow[t]{5}{*}{ I } & \multirow{3}{*}{ Outdoor } & Leafy vegetables & 26 & 9.7 & 5.3 & 8.4 & 1.7 & $3.0-23.0$ \\
\hline & & (Spinach) & 17 & 11.0 & 5.7 & 9.3 & 1.8 & $3.0-23.0$ \\
\hline & & Other green vegetables & 9 & 9.0 & 7.1 & 7.3 & 1.9 & $2.2-27.0$ \\
\hline & \multirow[t]{2}{*}{ Indoor } & Leafy vegetables & 14 & 11.0 & 5.8 & 9.9 & 1.7 & $4.2-24.0$ \\
\hline & & (Spinach) & 4 & 7.7 & 2.3 & 7.4 & 1.4 & $5.1-10.0$ \\
\hline
\end{tabular}

n, sample size; AM, arithmetic mean; SD, standard deviation; GM, geometric mean; GSD, geometric standard deviation. 
cultivation conditions ranged from 3.0-23 days ( $\mathrm{GM}=8.4$ days), and that for radiocesium ranged 3.1-8.9 days ( $\mathrm{GM}=$ 6.2 days). There were no significant differences between $T_{w}$ values of these radionuclides by $t$-test. In our recent publication, we carefully examined the fate of ${ }^{131} \mathrm{I}$ and radiocesium on plants, and we concluded that these similar $T_{w}$ values between ${ }^{131} \mathrm{I}$ and radiocesium may be affected by the crop mass increase (dilution effect) rather than decrease by weathering (e.g., wash-out with rain) [6, 8].

For $T_{w}$ values of Cs, leafy vegetables cultivated under outdoor and indoor conditions were different by Wilcoxon rank sum test $(p<0.01)$. Because the GM of $T_{w}$ of vegetables cultivated under indoor conditions was longer, it was expected that washing effect by rain caused this difference; however, the crop types were also different in these datasets, thus the analysis results may also be affected by the crop types/species as we found for $F_{B}$ of Cs.

Further comparison was carried using $T_{w}$ values for ${ }^{131} \mathrm{I}$; however, no difference was observed between $T_{w}$ s for outdoor ( $\mathrm{GM}=8.4$ days) and those for indoor ( $\mathrm{GM}=9.9$ days) cultivation conditions by Wilcoxon rank sum test. More specific data comparison was carried out using spinach $T_{w}$ data of ${ }^{131} \mathrm{I}$. Because the number of data was small for indoor cultivation $(n=4)$, the result was not reliable enough, but we did not find a difference between the conditions by Wilcoxon rank sum test. Moreover, we compared the $T_{w}$ of ${ }^{131}$ I data between leafy vegetables and other green vegetables grown under outdoor conditions, but we did not find a significant difference between these vegetable types as well.

From these results, it was difficult to explain why $T_{w}$ of Cs between crops grown under outdoor and indoor conditions was different, and vice versa, it was not clear why $T_{w}$ of ${ }^{131} \mathrm{I}$ between crops grown under outdoor and indoor conditions and different crop types was not different. Further studies are needed to clarify the weathering effect for these radionuclides.

\section{Conclusion}

In the present study, we reported $F_{B}$ and $T_{w}$ values of ${ }^{131} \mathrm{I}$ and radiocesium using openly available monitoring data obtained after the FDNPP accident. The purpose of this study was to provide environmental transfer parameter values to estimate activity concentrations of these radionuclides in agricultural crops when direct contamination occurred. The study results showed that there was no difference between
${ }^{131}$ I and radiocesium for both parameter values. The results showed that the $F_{B}$ values may be affected by crop types (shapes) and/or species but the difference was not clear for $T_{w}$ S. By using these values presented in this study, we would be able to carry out a rough estimation of the activity concentrations of ${ }^{131} \mathrm{I}$ and radiocesium in the edible part of leafy crops when these radionuclides were released into the atmosphere. However, because the effect of mass dilution by crop growth may lead to overestimation or underestimation, sufficient attention should be paid to apply these factors.

\section{Conflict of Interest}

No potential conflict of interest relevant to this article was reported.

\section{Author Contribution}

Conceptualization: Tagami K, Uchida S. Writing - original draft: Tagami K. Writing - review \& editing: Uchida S.

\section{Supplementary Materials}

Supplementary materials can be found via https://doi.org/ 10.14407/jrpr.2021.00164.

\section{References}

1. International Atomic Energy Agency. Handbook of parameter values for the prediction of radionuclide transfer in terrestrial and freshwater environments. Vienna, Austria: International Atomic Energy Agency; 2010.

2. International Atomic Energy Agency. Environmental transfer of radionuclides in Japan following the accident at the Fukushima Daiichi Nuclear Power Plant: report of working group 4 transfer processes and data for radiological impact assessment subgroup 2 on Fukushima data. Vienna, Austria: International Atomic Energy Agency; 2020.

3. Japanese Ministry of Health, Labour and Welfare. Database of radioactive substances in food [Internet]. Tokyo, Japan: Ministry of Health, Labour and Welfare; 2016 [cited 2021 Nov 1]. Available from http://www.radioactivity-db.info/.

4. Tagami K, Yasutaka T, Takada M, Uchida S. Aggregated transfer factor of ${ }^{137} \mathrm{Cs}$ in wild edible mushrooms collected in 2016-2020 for long-term internal dose assessment use. J Environ Radioact. 2021;237:106664.

5. Japan Atomic Energy Agency. Analysis of the activity concentra- 
tion of iodine- 131 by investigating the distribution of radioactive substances [Internet]. Tokai-mura, Japan: Japan Atomic Energy Agency; c2021 [cited 2011 Nov 1]. Available from: https://emdb. jaea.go.jp/emdb_old/en/portals/b1020101/.

6. Tagami K, Uchida S. Major factors affecting weathering half-lives of iodine-131 and radiocaesium in leafy vegetables directly contaminated by Fukushima Daiichi Nuclear Power Plant accident fallout. (1) Calculating weathering half-lives of leafy vegetables using data observed after the Fukushima nuclear accident. Radioisotopes. 2020;69(11):341-352.
7. Tagami K, Uchida S. Food processing retention factors for wild plants and rice. In: Proceedings of the 13rd Workshop on Environmental Radioactivity; 2012 Feb 27-29; Tsukuba, Japan. p. 154-159.

8. Tagami K, Uchida S. Major factors affecting weathering half-lives of Iodine-131 and radiocaesium in leafy vegetables directly contaminated by Fukushima Dai-ichi Nuclear Power Plant accident fallout. (2) Comparison of the weathering half-lives observed for herbaceous plants after the Chernobyl and the Fukushima nuclear accidents. Radioisotopes. 2020;69(11):353-364. 